\title{
Patologias sociais na metrópole de São Paulo: análise socioespacial de indicadores nas subprefeituras
}

\author{
Graziela Serroni Perosa \\ Universidade de São Paulo / Escola de Artes, Ciências e Humanidades \\ São Paulo / SP - Brasil
}

Cristiane Kerches da Silva Leite

Universidade de São Paulo / Escola de Artes, Ciências e Humanidades

São Paulo / SP - Brasil

\section{Francisco César Pinto da Fonseca}

Fundação Getulio Vargas / Escola de Administração de Empresas de São Paulo, Departamento de Gestão Pública

Pontifícia Universidade Católica de São Paulo

São Paulo / SP - Brasil

\section{Frédéric Lebaron}

Universidade de Versailles Saint-Quentin-em-Yvelines

Universidade Paris-Sarclay

Sciences Po Saint-Germain-em-Laye

Versailles / Paris - França

\begin{abstract}
Objetiva-se discutir a importância de análises multideterminadas para a gestão de políticas públicas no âmbito da administração pública. A partir do Censo de 2010 discutem-se as disparidades econômicas e sociais entre as subprefeituras do município de São Paulo por meio do método de análise de componentes principais (ACP) com base nas dimensões derivadas do Índice de Saúde Social, indicador que fornece panorama mais complexo do que o Índice de Desenvolvimento Humano (IDH). A análise multideterminada baseia-se na noção de "espaço social" (Bourdieu) e possibilita valioso instrumento de diagnóstico e impacto de políticas públicas, articulando múltiplas dimensões dos fenômenos sociais. Conclui-se que, pelo método da ACP, é possível observar como os indicadores tradicionais ocultam sutilezas e diferenças quanto às desigualdades de territórios aparentemente homogêneos.
\end{abstract}

Palavras-chave: indicadores sociais; patologias sociais; espaço social; gestão de políticas públicas.

DOI: http://dx.doi.org/10.1590/0034-7612151585

Artigo recebido em 2 jul. 2015 e aceito em 2 jun. 2016. 
Patologías sociales en la metropolis de São Paulo: análisis de indicadores socio-espacial en sub-prefecturas

El objetivo es analizar la importancia del análisis multideterminadas para la gestión de las políticas públicas de la administración pública. Desde el Censo de 2010 se analizan las diferencias económicas y sociales entre los municipios de San Pablo a través de la metodología del análisis de componentes principales (PCA), a partir de las dimensiones derivadas del Índice de Salud Social, un indicador que proporciona información general más complejo que el Índice de Desarrollo humano (IDH). El análisis multifactorial se basa en la noción de "espacio social" (Bourdieu) y proporciona una valiosa herramienta de diagnóstico y el impacto de las políticas públicas, la coordinación de múltiples dimensiones de los fenómenos sociales. En conclusión, por medio de método de la ACP , es posible observar cómo los indicadores tradicionales ocultam sutilezas y diferencias con respecto a las desigualdades de territorios aparentemente homogéneos.

Palabras clave: indicadores sociales; patologías sociales; espacio social; gestión de las políticas públicas.

Social pathologies in the great Metropolis of São Paulo: socio-spatial analysis of indicators in the boroughs

The objective here is to discuss the importance of multi-determined analyses to the management of public policies within the scope of public administration. Using the Census of 2010, we look at the economic and social disparities that existed between the different boroughs of the City of São Paulo by adopting the principal component analysis method (PCA), based on dimensions derived from Social Health Index, an indicator that provides a more complex overview than the Human Development Index (HDI). The multi-determined analysis is based on the notion of "social space" (Bourdieu) and provides a valuable tool for diagnosing the impact of public policies, coordinating the multiple dimensions of social phenomena. We concluded that, by using the PCA method, it is possible to observe how the traditional indicators hide certain subtleties and differences with regard to inequalities between apparently homogeneous territories.

KEYWORDs: social indicators; social pathologies; social space; public policy management.

\section{Introdução}

Este artigo analisa as disparidades econômicas e sociais que caracterizam a aglomeração urbana de São Paulo e a configuração de fenômenos relacionados com as patologias sociais. Estas são aqui definidas como situações de anomia e perda de legitimidade das normas sociais, por vezes fenômenos de baixa incidência estatística, concebidos sob a ótica durkheiminiana como o produto de dinâmicas estruturais da sociedade e irredutíveis às intenções dos indivíduos. ${ }^{1}$

\footnotetext{
${ }^{1}$ Ver: Durkheim (2011); Baudelot e Establet (2006); Lebaron (2011). Note-se tratar-se de interpretação contemporânea da perspectiva durkheiminiana, distanciando-se do conservadorismo representado no século XIX e na primeira metade do século XX.
} 
Objetiva-se relacionar indicadores concernentes às condições objetivas de vida da população (renda, educação e infraestrutura pública) com as dimensões sociais mais "subjetivas", apreendidas por meio de um conjunto de indicadores de "saúde" e de "patologias sociais", expressos nas taxas de suicídio, gravidez antes dos 15 anos, abandono do ensino médio, agressão às mulheres e às crianças etc.

Trata-se de perspectiva diretamente inspirada no relatório de Stiglitz, Sen e Fitoussi (2009), sobretudo quanto à mensuração da "qualidade de vida", ou seja, relativas às diferentes dimensões da vida social que não necessariamente "monetárias" ou econômicas. Essa perspectiva tem sido discutida em diferentes pesquisas comparadas sobre os fatores explicativos para os níveis de "desenvolvimento humano" entre os países, para além das dimensões econômicas, como o PIB (Gadrey e Jany-Catrice, 2006; Miringoff e Opdycke, 2008; Stiglitz, Sen e Fitoussi, 2009; Veiga, 2008; Lebaron, 2011).

Por meio de um estudo exploratório de indicadores sociais das subprefeituras de São Paulo, baseado na técnica de análise de componentes principais (ACP), identificam-se correlações estatísticas nos diferentes territórios e os níveis de "saúde social" das subprefeituras. O objetivo específico é identificar estatisticamente as relações entre condições de vida - expressas por indicadores sociais de renda, escolaridade, habitação, expectativa de vida - e a distribuição do conjunto de indicadores de patologias sociais disponíveis sobre as subprefeituras de São Paulo, visando a contribuir para a análise das políticas públicas do município.

Além das taxas de violência física ${ }^{2}$, a pesquisa incluiu a análise de indicadores provenientes de outras formas de violência mais sutis, caso da violência simbólica (Bourdieu, 1998), que se caracterizam por não serem apercebidas como tal: reprovação escolar de mais de dois anos, medida pela taxa de disfunção entre série/idade; agressão extrema contra si mesmo, medida pelas taxas de suicídio, entre outras.

O estudo analisou os dados do Censo 2010/IBGE sobre a situação das 31 subprefeituras do município de São Paulo 3 num universo formado por mais de 3 milhões de domicílios e uma população de mais de 11 milhões de habitantes, e cuja região metropolitana possui cerca 20 milhões de habitantes e um dos 10 maiores PIB do mundo. ${ }^{4}$ Trata-se de universo complexo e multifacetado, com imensas diversidades resultantes tanto das sucessivas ondas de imigração e migração, ao longo dos séculos, como da dinâmica profundamente desigual do capitalismo brasileiro.

Atualmente, o IDH do município está em torno de 0,8 (considerado alto), ocultando as grandes diferenças sociais entre as regiões da cidade. Coexistem extrema pobreza e extrema riqueza e, sobretudo, territórios heterogêneos quanto às dinâmicas econômica, social, cultural

\footnotetext{
${ }^{2}$ As taxas de violência física no estado de São Paulo, particularmente a taxa de homicídios, são objeto de controvérsias, tendo em vista serem produzidas pela Secretaria Estadual de Segurança Pública, que está diretamente implicada no fenômeno mensurado.

${ }^{3}$ Este estudo não incorporou indicadores referentes à 32 2 subprefeitura, Sapopemba, que fora desmembrada da subprefeitura de Vila Prudente e instituída em 2013. Portanto, os dados referem-se à então subprefeitura de Vila Prudente, que incorporava os distritos de Sapopemba, Vila Prudente e São Lucas.

${ }^{4}$ Disponível em: <http://infocidade.prefeitura.sp.gov.br/htmls/13_maiores_pibs_urbanos_2008_10509.html>.
} 
e urbanística. Mesmo considerando a redução da desigualdade no país desde $2000,{ }^{5}$ o coeficiente de Gini do município cresceu entre 1990 e $2010 .^{6}$

Optou-se por utilizar como unidade de análise as subprefeituras por serem as unidades administrativas mais descentralizadas. Assim, este estudo objetiva identificar e visibilizar as especificidades das diferentes configurações urbanas e oferecer elementos para que a ação pública possa ser mais eficaz no combate às patologias sociais observadas.

O texto está organizado nas seguintes seções: a primeira trata, de forma sucinta, da trajetória histórica das gerações de indicadores, das desigualdades e das patologias sociais. A segunda seção explicita a metodologia do trabalho; a terceira apresenta e analisa os resultados; e a última apresenta as considerações finais. Deve-se ressaltar que, embora a perspectiva de análise de indicadores por meio da ACP esteja inserida fortemente no campo da administração pública, na medida em que as modernas formas de gestão baseiam-se vigorosamente no uso de indicadores, ainda é escassa sua utilização no "campo de públicas". ${ }^{7}$ Nesse sentido, este texto pretende preencher modestamente esse vácuo, estimulando outros pesquisadores a refletirem sobre novas abordagens sociais dos indicadores no âmbito das políticas públicas e da administração pública. Em outras palavras, trata-se do espaço interdisciplinar e aplicado de ações tecnopolíticas em que o Estado, particularmente os governos, procuram resolver problemas sociais relevantes (Farah, 2011). Portanto, os indicadores, sobretudo os mais sutis, sensíveis e sofisticados, são cruciais ao "campo de públicas" como instrumentos determinantes de diagnóstico e construção de alternativas.

\section{Gerações de indicadores sociais, desigualdades e patologias sociais}

Planejar e avaliar ações governamentais no âmbito da gestão pública e das políticas sociais é indissociável do uso de indicadores como instrumentos poderosos que "expressam uma síntese de informações quantitativas ou qualitativas sobre um fenômeno social relevante" (Mokate, 2002). A emergência do debate sobre indicadores sociais, nas décadas de 1960 e 1970, teve origem na insatisfação de gestores e pesquisadores de diferentes instituições nacionais e internacionais em relação aos indicadores estritamente econômicos que dominavam amplamente as estatísticas públicas (Gadrey e Jany-Catrice, 2006; Stiglitz, Sen e Fitoussi, 2009; Veiga, 2008; Jannuzzi, 2011, 2004; Lebaron, 2011).

\footnotetext{
${ }^{5}$ Disponível em: <www.ipea.gov.br/digital/publica_003.html>. Acesso em: 30 jun. 2015.

${ }^{6}$ Disponível em: <http://tabnet.datasus.gov.br/cgi/ibge/censo/cnv/ginisp.def>. Acesso em: 30 jun. 2015.

${ }^{7}$ Quanto ao campo de públicas, foi realizada pesquisa no sítio do Scielo dos seguintes periódicos da área de administração e administração pública, em números recentes: Cadernos EBAPE.BR; Organizações \& Sociedade; Revista de Administração Mackenzie; Revista Eletrônica de Administração (Porto Alegre); Revista de Administração (São Paulo); Revista de Administração Contemporânea; Revista de Administração Pública; Revista de Administração de Empresas. Foram encontrados os seguintes textos sobre análise de indicadores sociais e políticas públicas: Van Bellen (2004); Vieira et al. (2000); Faria, Jannuzzi e Silva (2008); Reis, Silveira e Rodrigues (2012); Scriptore e Toneto Júnior (2012); Fonseca, Beltrão e Prado (2013).
} 
A análise, em perspectiva histórica, sobre o uso de indicadores sociais permite identificar gerações relacionadas com os paradigmas de desenvolvimento econômico e social e suas respectivas políticas sociais, em distintos contextos. A primeira geração de indicadores surgiu no pós-guerra, coroando o PIB e o PIB per capita como as grandes referências de desenvolvimento, refletindo a criação da riqueza em si e a ideia de que desenvolvimento se retringe a crescimento econômico (Paulani e Braga, 2006).

Com o avanço dos sistemas de bem-estar social e das políticas keynesianas nas décadas de 1950 e 1960, criou-se a cultura de valorização dos indicadores sociais como instrumentos capazes de desenvolver instrumentos de mensuração do bem-estar e da mudança social que incorporassem novas dimensões investigativas (Jannuzzi, 2004). Por isso, as desvantagens do PIB como parâmetro do desenvolvimento econômico e social tornavam-se progressivamente evidentes, deslegitimando-o. Entre as críticas que surgiram destaca-se o fato de não refletir concepção de desenvolvimento mais ampla e não contemplar dissonâncias entre crescimento e desenvolvimento, comuns em situações de grande desigualdade de renda.

Na década de 1970 os sistemas de indicadores sociais entraram em crise, em paralelo ao modelo keynesiano. Na passagem para a década de 1980, diante da ascensão das ideias liberais em vários países, inclusive no Brasil e na América Latina, iniciou-se um "contramovimento": experiências locais e participativas de formulação e implementação de políticas públicas repensaram a concepção de indicadores sociais por atores estatais e não estatais, num contexto de crise econômica e redemocratização, apontando para o esgotamento dos indicadores tradicionais.

Esses processos culminaram com a retomada do debate sobre desenvolvimento e deram origem à segunda geração de indicadores, a partir da criação do Índice de Desenvolvimento Humano (IDH), nos anos 1990. Criado pelo economista paquistanês Mahbub ul Haq com a colaboração do economista indiano Amartya Sen, representou importante inovação no campo dos indicadores de desenvolvimento econômico e social. Representou tentativa de operacionalizar diversas dimensões sociais, tais como renda, saúde e educação, em um indicador composto: o desenvolvimento como meio para a expansão das "capacidades humanas" e não como produção da riquezas materiais (Gaudrey e Jany-Catrice, 2006; Veiga, 2008). O IDH representou avanço na trajetória dos indicadores sociais, pois sinalizou que somente o crescimento econômico não explicaria o complexo processo de desenvolvimento social.

A despeito do avanço que representou em perspectiva histórica, os atuais desafios das políticas públicas no Brasil e em outros países que demandam instrumentos de análise de diferentes territórios - no âmbito da administração pública —, em termos de dimensões e de complexidade social, o IDH se apresenta como instrumento problemático. Baseado em médias nacionais, oblitera as disparidades territoriais das unidades menores, ou seja, mascara situações extremas. Neste texto, essa questão é fundamental na medida em que se busca revelar as diferenças e nuances intramunicipais no município de São Paulo. O IDH também se mostra conceitualmente insatisfatório ao reificar medida única de desenvolvimento em detrimento de sua multidimensionalidade (Jannuzzi, 2011). Por isso, neste estudo são agregados outros indicadores a partir do conceito de saúde social que, vistos em conjunto, oferecerem instru- 
mento de análise alternativo para o planejamento das ações na administração pública das subprefeituras.

Nos anos 2000, avançando em relação à primeira e à segunda geração de indicadores, surgiram outros que consideraram as políticas públicas processo a ser aprimorado ao longo do tempo, com reavaliação de metas e objetivos (Kayano e Caldas, 2002; Veiga, 2008). Tais indicadores de terceira geração são mais adequados ao perfil das políticas públicas, permitindo mensurar processos de mudança econômica e social que, no Brasil das últimas décadas, têm se revelado de forma bastante heterogênea, com intensidades e dinâmicas locais próprias. Ao destacar-se a categoria analítica "território" como espaço de construção de políticas públicas, da municipalização das políticas sociais ${ }^{8}$ e da ampliação de práticas democráticas na gestão pública, os indicadores de terceira geração tornaram-se estratégicos na formulação, implementação e avaliação de políticas. ${ }^{9}$

Os instrumentos de medida de desigualdade social e do bem-estar desenvolvidos ao longo do século XX deram origem à vasta produção de estatísticas que se consolidaram como ferramentas à formulação de políticas públicas no século XXI. Desde o relatório de Stiglitz, Sen e Fitoussi (2009) busca-se integrar fenômenos até então pouco relacionados, como as diferentes dimensões do bem-estar e das desigualdades sociais, para além das desigualdades de renda. Essa renovação é particularmente interessante para retomar problemas sociológicos "clássicos", tais como as patologias sociais de Durkheim, cujos estudos sobre as taxas de suicídio voltaram a ser revalorizados a partir dos trabalhos de Baudelot e Establet $(2006,1992)$ para analisar o contexto do final do século XX e início do XXI.

Com efeito, uma longa tradição de estudos sociológicos sugere a necessidade de análises empíricas sobre dinâmicas econômicas específicas do capitalismo e suas consequências sobre o bem-estar, a "saúde" e as "patologias sociais". Lazarsfeld, Jahoda e Zeisel (1981) estudaram com minúcia os efeitos mais "subjetivos" da desindustrialização do município de Marienthal, na Áustria, em 1930. Castel (2012), abordando as metamorfoses da "questão social" na Europa, aponta de que maneira o crescimento do trabalho informal e precário gera "desafiliação", isolamento, perda de coesão social e "anomia", no sentido da releitura de Durkheim (Sennett, 1998).

Na mesma direção, estudos epidemiológicos recentes corroboram a forte relação entre os níveis de desigualdade social e os indicadores de saúde (Wilkinson, 2005; Buss e Pellegrini Filho, 2007). Stuckler e Basu (2013) focalizam as consequências de políticas de austeridade fiscal sobre tais indicadores, associando redução de investimentos públicos em políticas de bem-estar social com a piora de indicadores de saúde.

As reflexões de Pierre Bourdieu (1998) e de Amartya Sen (2000, 2007) inspiraram o desenvolvimento da perspectiva de análise baseada em fatores ao mesmo tempo objetivos e

\footnotetext{
${ }^{8}$ Sobre municipalização das políticas sociais, ver: Kugelmas (2001); Arretche (2012); Leite e Fonseca (2011).

${ }^{9}$ Sobre os indicadores de Terceira Geração, como o Índice Paulista de Responsabilidade Social (IPRS) e o Índice Paulista de Vulnerabilidade Social (IPVS), ver: Kayano e Caldas (2002) e Veiga (2008).
} 
"subjetivos" da vida social. Dessa forma, na esteira das recomendações do relatório de Stiglitz, Sen e Fitoussi (2009) emprega-se como ferramenta de análise a distribuição de indicadores entre os grupos sociais que apontam os limites do uso da média e da mediana para apreender a realidade de sociedades fortemente desiguais.

\section{Metodologia}

No âmbito dessas preocupações relativas aos efeitos das dinâmicas econômicas sobre os indivíduos, relaciona-se, neste estudo, um conjunto de indicadores de "saúde" ou de "patologias" sociais com as condições objetivas de vida da população entre as 31 subprefeituras de São Paulo, conforme o mapa a seguir.

Para obter a síntese multidimensional e, ao mesmo tempo, estrutural das condições de vida no município de São Paulo, a análise baseou-se no conceito de "espaço social", definido a partir de princípios de diferenciação pertinentes ao conjunto da população, em razão de diferentes formas de capital: econômico, cultural, social, simbólico (Bourdieu, 1979; 2011). Nessa perspectiva, os grupos de indivíduos são definidos por suas posições relativas às condições de vida objetivas que a posse de diferentes formas de capital e do tipo de infraestrutura pública dos territórios possibilita. A distribuição das patologias sociais na cidade não é aleatória, pois relacionada tanto com a pobreza e com a miséria como com o desenvolvimento econômico e, portanto, com a riqueza e com as posições sociais intermediárias. Para além da oposição esperada entre os extremos da estrutura social, outros fatores emergem como decisivos, como a posse do capital cultural intermediário (diploma de ensino médio) e as relações de gênero, especialmente se se considerar o contexto mais amplo de aumento da escolaridade e da taxa de emprego feminino (Bruschini e Lombardi, 2002; Baudelot e Establet, 2006).

Os dados primários das 31 subprefeituras do município de São Paulo foram coletados do banco de dados Infocidade, produzido pela Secretaria de Desenvolvimento Urbano da prefeitura de São Paulo, que disponibiliza dados extraídos dos censos demográficos, agregados por subprefeitura e distritos. Complementou-se essa base de dados com informações da Fundação Seade e do Observatório Cidadão, que também reúne dados dos censos demográficos e de diferentes registros administrativos, disponibilizados por distritos e subprefeituras de São Paulo. ${ }^{10}$

Para reconstruir o "espaço social" de São Paulo optou-se por defini-lo a partir de indicadores sociodemográficos (renda, escolaridade, infraestrutura pública etc.). Ao procurar caracterizar diferentes formas de capital (nos termos de Bourdieu), lançou-se luz sobre as fronteiras entre frações dos grupos populares e das classes médias e altas, distinções assentadas especialmente no conceito de "estatuto dos diplomas", como sugerem estudos clássicos da sociologia e do papel do sistema de ensino na reprodução da hierarquia social (Ringer, 2001; Weber, 1974).

\footnotetext{
${ }^{10}$ Ver Infocidade (<http://infocidade.prefeitura.sp.gov.br/>) e Observatório Cidadão (<www.nossasaopaulo.org. br/observatorio/ $>$ ).
} 
Figura 1

Mapa das subprefeituras e distritos do município de São Paulo

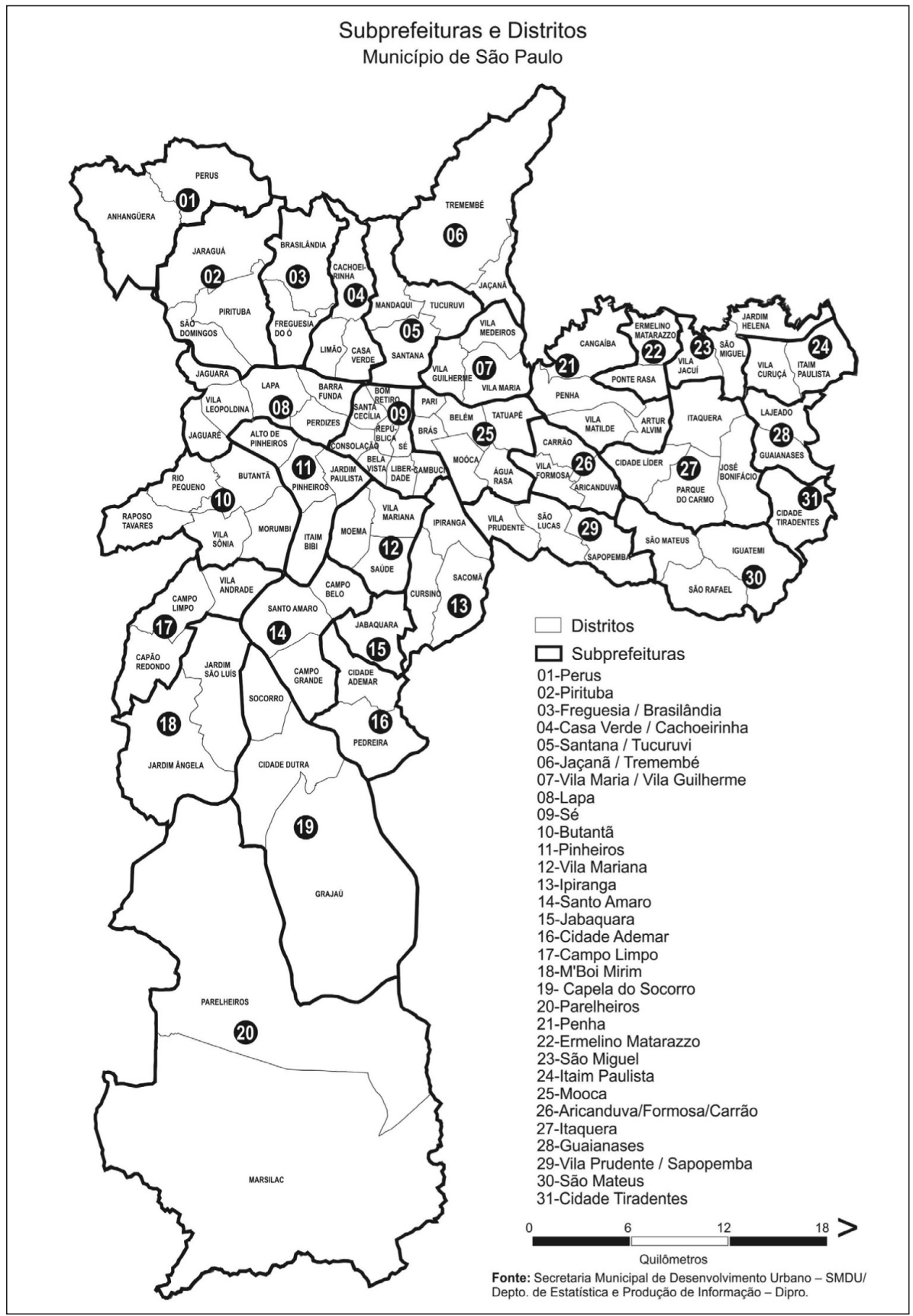

Fonte: Secretaria Municipal de Desenvolvimento Urbano (SMDU)/Departamento de Estatística e Produção de Informação (Dipro). Disponível em: <www.prefeitura.sp.gov.br/cidade/secretarias/desenvolvimento_urbano/ dados_estatisticos/>. Acesso em: 2 maio 2016. 
A pesquisa não dispunha de estatísticas públicas sobre as categorias socioprofissionais da população, agrupadas por subprefeituras. ${ }^{11}$ Todavia, informações detalhadas sobre o nível de renda domiciliar mensurado em salários mínimos e o nível educacional foram extremamente úteis para definir o espaço social (quadro 1). Foram inseridas duas variáveis demográficas relativas à idade das pessoas, contornando assim a ausência de informações sobre a taxa de fecundidade e da expectativa de vida, disponíveis apenas para o conjunto da cidade. Em relação ao nível educacional, três variáveis foram tomadas como indícios de "capital escolar e cultural": uma primeira variável majoritária, formada pelos que não completaram o ensino fundamental II (37,5\%); outra constituída por aqueles que concluíram o ensino médio (26\%); e os que possuem o diploma de ensino superior: $16 \%{ }^{12}$ As variáveis "leitos públicos", "matrículas públicas no ensino médio", "bibliotecas públicas" e "domicílios sem esgoto" complementaram o conjunto de variáveis ativas como síntese da infraestrutura pública disponível. A seguir encontra-se o quadro das variáveis ativas:

\section{Quadro 1}

\section{As variáveis ativas}

\begin{tabular}{|c|c|}
\hline 15 VARIÁVEIS ATIVAS & DEFINIÇÕES \\
\hline População com mais de 60 anos & Percentual da população com mais de 60 anos. ${ }^{1}$ \\
\hline População com menos de 14 anos & Percentual da população com menos de 14 anos. ${ }^{1}$ \\
\hline $\begin{array}{l}\text { Sem instrução e com ensino } \\
\text { fundamental II incompleto }\end{array}$ & $\begin{array}{l}\text { Percentual da população de } 10 \text { anos ou mais sem instrução ou ensino } \\
\text { fundamental incompleto.' }\end{array}$ \\
\hline Ensino Médio completo & $\begin{array}{l}\text { Percentual da população de } 10 \text { anos ou mais com ensino médio completo ou } \\
\text { superior incompleto.' }\end{array}$ \\
\hline Ensino Superior & Percentual da população de 10 anos ou mais com ensino superior completo.' \\
\hline Renda de até meio salário mínimo ${ }^{12}$ & Domicílios por Faixa de Rendimento, em salários mínimos. ${ }^{1}$ \\
\hline Renda entre 1-2 SM & Domicílios por Faixa de Rendimento, em salários mínimos. ${ }^{1}$ \\
\hline Renda entre $2-5$ SM & Domicílios por Faixa de Rendimento, em salários mínimos. ${ }^{1}$ \\
\hline
\end{tabular}

\footnotetext{
11 Tais informações foram tratadas por Marques (2014), que descreve o panorama detalhado das ocupações dos diferentes grupos sociais em São Paulo. À época da realização desta pesquisa tais dados não estavam disponíveis, por regiões da cidade, em nenhuma das bases consultadas.

${ }^{12}$ Agregou-se em uma mesma categoria o percentual dos que não possuíam instrução, os que concluíram o nível primário e os que não concluíram o ensino fundamental II. Nos primeiros testes, quando essas categorias foram utilizadas separadamente, viu-se que essa população ocupava a mesma posição no espaço social. Por isso criou-se uma única categoria para a faixa de menor escolaridade, que corresponde, portanto, aos que não concluíram a antiga oitava série, hoje nono ano do ensino fundamental II.

${ }^{13}$ O salário mínimo no Brasil aumentou de R\$ 151,00 (2000) para R\$ 510,00 (2010).
} 


\begin{tabular}{|c|c|}
\hline 15 VARIÁVEIS ATIVAS & DEFINICCÕES \\
\hline Renda entre 5-10 SM & Domićlios por Faixa de Rendimento, em salários mínimos.' \\
\hline Renda maior 20 SM & Domićlios por Faixa de Rendimento, em salários mínimos.' \\
\hline Emprego Formal feminino & Empregos formais, exclusive administração pública, segundo gênero.² \\
\hline Leitos públicos & Total de leitos em hospitais públicos. ${ }^{1}$ \\
\hline Matrícula Ensino Médio Público & Percentual de matrícula no ensino médio público (estadual e municipal). ${ }^{3}$ \\
\hline Domicílios sem esgoto & Total de domicílios sem esgoto.' \\
\hline Bibliotecas Públicas & Disponibilidade de bibliotecas públicas e acervo. ${ }^{4}$ \\
\hline
\end{tabular}

Fonte: 'IBGE/Censo Demográfico 2010; ${ }^{2}$ Ministério do Trabalho e Emprego. Relação Anual de Informações Sociais - Rais, $2010 ;{ }^{3}$ Censo Escolar MEC/Inep, 2008; ${ }^{4}$ Secretaria Municipal de Cultura/SMC - Departamento de Bibliotecas/SMDU-Dipro, 2010; elaboração dos autores. Disponíveis em: <http://infocidade.prefeitura.sp.gov.br/>; <www.nossasaopaulo.org.br/observatorio/>. Acesso em: 15 jan. 2015.

Em seguida procedeu-se à escolha das variáveis definidas como patologias sociais, inseridas como "variáveis suplementares" e projetadas sobre o "espaço social", definido pelos eixos principais que resumem a variância total da nuvem de pontos. A referência básica foi o Índice de Saúde Social (ISS, The Index of Social Health), desenvolvido por Marque-Luisa Miringoff e Sandra Opdycke, em 1987, no Institute for Innovation in Social Policy da Vassar College (NY), como alternativa aos indicadores econômicos e ao IDH, cujo objetivo era aprofundar a medida do bem-estar social. ${ }^{14}$ Algumas variáveis desse índice estadunidense, também pertinentes para a realidade de São Paulo — como a insegurança alimentar, o suicídio de adolescentes, a toxicomania e a pobreza de idosos —, não estavam disponíveis.

Como critério para a escolha deste segundo conjunto de variáveis buscou-se reunir informações sobre "problemas sociais" derivados de dinâmicas estruturais do capitalismo, notadamente vigentes no Brasil, ligados tanto à pobreza e à miséria como ao desenvolvimento e à riqueza (Lebaron, 2013). Foram incluídos indicadores capazes de exprimir os efeitos perversos do desenvolvimento econômico, ligados à pobreza e à precariedade das condições de vida, que se constituem em zonas de "vulnerabilidade", "incerteza" e "infortúnio" (Castel, 2012). No quadro 2 encontram-se os indicadores de patologias sociais.

\footnotetext{
${ }^{14}$ Este indicador sintético combina 16 dimensões para medir a distribuição do bem-estar e diz respeito a todas as faixas etárias: mortalidade infantil, pobreza infantil, violência contra crianças, suicídio de adolescentes, toxicomania, abandono dos estudos secundários, taxa de desemprego, nível de salários, cobertura de saúde privada, pobreza de idosos, custos da saúde priváda entre idosos, homicídios, acidentes de tráfego ligados ao álcool, insegurança alimentar, acesso à propriedade e Índice de Gini (Miringoff e Opdycke, 2008).
} 
Quadro 2

15 indicadores de patologias sociais

\begin{tabular}{|c|c|}
\hline VARIÁVEIS & DEFINIÇÕES E FONTES \\
\hline Desemprego & Taxa média de desemprego $1 ; 10$ \\
\hline Mortalidade infantil & Número de óbitos de crianças menores de um ano por mil nascidas vivas ${ }^{1 ; 10}$ \\
\hline Mortalidade no trânsito & Número de óbitos por acidentes de trânsito em 100 mil habitantes ${ }^{2 ;} 10$ \\
\hline Gravidez até 15 anos & Percentual de nascidos vivos de mães com até 15 anos $^{4 ;} 10$ \\
\hline Homicídios & Número de mortes por homicídio por 100 mil habitantes $2 ; 10$ \\
\hline Suicídios & Número de mortes qualificadas como suicídios $2 ; 10$ \\
\hline Analfabetismo & Taxa de analfabetismo da população de 15 anos ou mais $5 ; 10$ \\
\hline $\begin{array}{l}\text { Abandono do Ensino } \\
\text { Médio }\end{array}$ & Porcentagem de alunos que abandonaram o ensino médio nas redes pública e privada ${ }^{6 ; 1}$ \\
\hline Disfunção Série/Idade & $\begin{array}{l}\text { Porcentagem de alunos com dois anos ou mais de defasagem em relação à idade ideal para as } \\
\text { séries do ensino fundamental II nas redes públicas e privadas }{ }^{7} 11\end{array}$ \\
\hline Agressão à mulher & $\begin{array}{l}\text { Número de internações de mulheres de } 20 \text { a } 59 \text { anos por causas relacionadas com possíveis } \\
\text { agressões por } 100 \text { mil habitantes }{ }^{3 ; 11}\end{array}$ \\
\hline Agressão a crianças & $\begin{array}{l}\text { Número de internações de crianças de } 0 \text { a } 14 \text { anos por causas relacionadas com possíveis } \\
\text { agressões por } 100 \text { mil habitantes }{ }^{3 ; 11}\end{array}$ \\
\hline Mortalidade por tumor & Taxa de óbitos dos residentes por causas, tumores (T02)2; 10 \\
\hline $\begin{array}{l}\text { Mortalidade por } \\
\text { transtorno mental }\end{array}$ & Taxa de óbitos dos residentes por transtorno mental2; 10 \\
\hline Chefia familiar feminina & Responsável pelo domicílio por gênero ${ }^{8 ;} 1$ \\
\hline Áreas contaminadas & Número de unidades territoriais contaminadas ${ }^{9}$ \\
\hline
\end{tabular}

Fonte: Elaboração dos autores a partir dos seguintes bancos de dados: 'seade/Dieese, 2010; ${ }^{2}$ PRO-AIM/SMS-CET/SMT-SFMSP, 2011 ; ${ }^{3} \mathrm{AlHs} /$ datasus, 2010; ${ }^{4}$ sinasc e SMS, 2011 ; ${ }^{5}$ Censo demográfico, IBGE, 2010; ${ }^{6}$ Censo Escolar/Inesp, $2011 ;{ }^{7} \mathrm{CIE} /$ Secretaria de Estado da Educação, 2011; ${ }^{8}$ Censo demográfico, IBGE, 2000; ${ }^{9}$ Secretaria Municipal do Verde/GTAC, 2015; ${ }^{10}$ disponíveis no Infocidade (<http://infocidade.prefeitura.sp.gov.br/>; ${ }^{11}$ Observatório Cidadão/Rede Nossa São Paulo (<www.nossasaopaulo.org.br/>). Acesso em: 15 jan. 2015.

Neste estudo inclui-se ainda um conjunto de fenômenos relacionados ao desenvolvimento econômico e social: desde a mortalidade por acidente de trânsito e áreas de contaminação ambiental à trajetória de alunos nos sistemas de ensino. Nesse sentido, as variáveis abandono do ensino médio, analfabetismo e distorção série-idade possibilitam pensar diferentes formas de patologias sociais.

Mais ainda, ao inserir variáveis relativas à dimensão sobre "relações de gênero" procurou-se captar os possíveis efeitos de fenômenos mais recentes na estrutura do espaço multidi- 
mensional, tais como o crescimento da participação feminina na escolarização e no mercado de trabalho, a redução da taxa de fecundidade e o crescimento da chefia familiar das mulheres (Bruschini e Lombardi, 2002; Berquó e Cavenaghi, 2006).

Dessa forma, as variáveis "chefia familiar feminina", "agressão às crianças" e "agressão às mulheres" revelaram-se particularmente relevantes. Vale sublinhar que os indicadores de agressão provêm de registros do sistema de saúde (DataSUS) e correspondem a casos extremos: número de mulheres e crianças hospitalizadas por agressão, isto é, dados que possuem a vantagem de contornar parcialmente o problema da notificação desigual desses fenômenos entre diferentes grupos sociais, como sugerem estudos qualitativos. A taxa de "chefia familiar feminina" foi considerada um indicador de "patologia social" na medida em que pode apontar para situação de "desafiliação" (Castel, 2012) e de maior vulnerabilidade econômica e social, como sugerem outros indicadores sociais, como o Índice Paulista de Vulnerabilidade Social (IPVS). Entre 2000 e 2010, por exemplo, houve aumento significativo do número de domicílios com chefia familiar feminina no município de São Paulo, que passou de $29,1 \%$ para 44,1\%, sobretudo nas regiões nas quais a taxa de escolarização e o nível de renda são mais altos. ${ }^{15}$

Como as variáveis escolhidas não estavam na mesma escala, a técnica de análise de componentes principais standard (ACP) possibilitou construir representação estrutural do espaço social com a projeção do conjunto de patologias sociais. A ACP Standard organiza as variáveis em uma escala comum e lhes confere a mesma importância na determinação dos eixos principais que definem o espaço. A partir das 14 variáveis ativas (quadro 1). Esta técnica atribui a mesma importância teórica às diferentes dimensões, normalizando as variáveis e hierarquizando os fatores que determinam a estrutura do espaço. Portanto, a interpretação dos resultados da ACP se apoia num conjunto de valores numéricos dos eixos e das nuvens de pontos no espaço referentes às condições de vida, estruturado por dimensões principais (eixo 1 e eixo 2).

\section{Apresentação e análise dos resultados}

A análise dos resultados se baseia primeiro na observação dos eixos e em seguida das nuvens de subprefeituras. Por último, apresenta correlações encontradas entre as patologias sociais e os eixos, bem como associações entre as formas de patologias. As subprefeituras estão representadas como nuvens de pontos distribuídas ao longo de eixos principais (figura 1). Entre os cinco eixos identificados, serão interpretados a seguir o Eixo 1, que responde por 59,8\% da variância; o Eixo 2, por 16,4\%; e o Eixo 3, por 8,9\% (figuras 2 e 3). A seguir, encontra-se a análise dos eixos 1 e 2 .

\footnotetext{
${ }^{15}$ Esta taxa refere-se a todas as mulheres chefes de família (aquelas que vivem sozinhas e as que são responsáveis pelo domicílio).
} 
Figura 2

Nuvens de subprefeituras e o espaço social de São Paulo

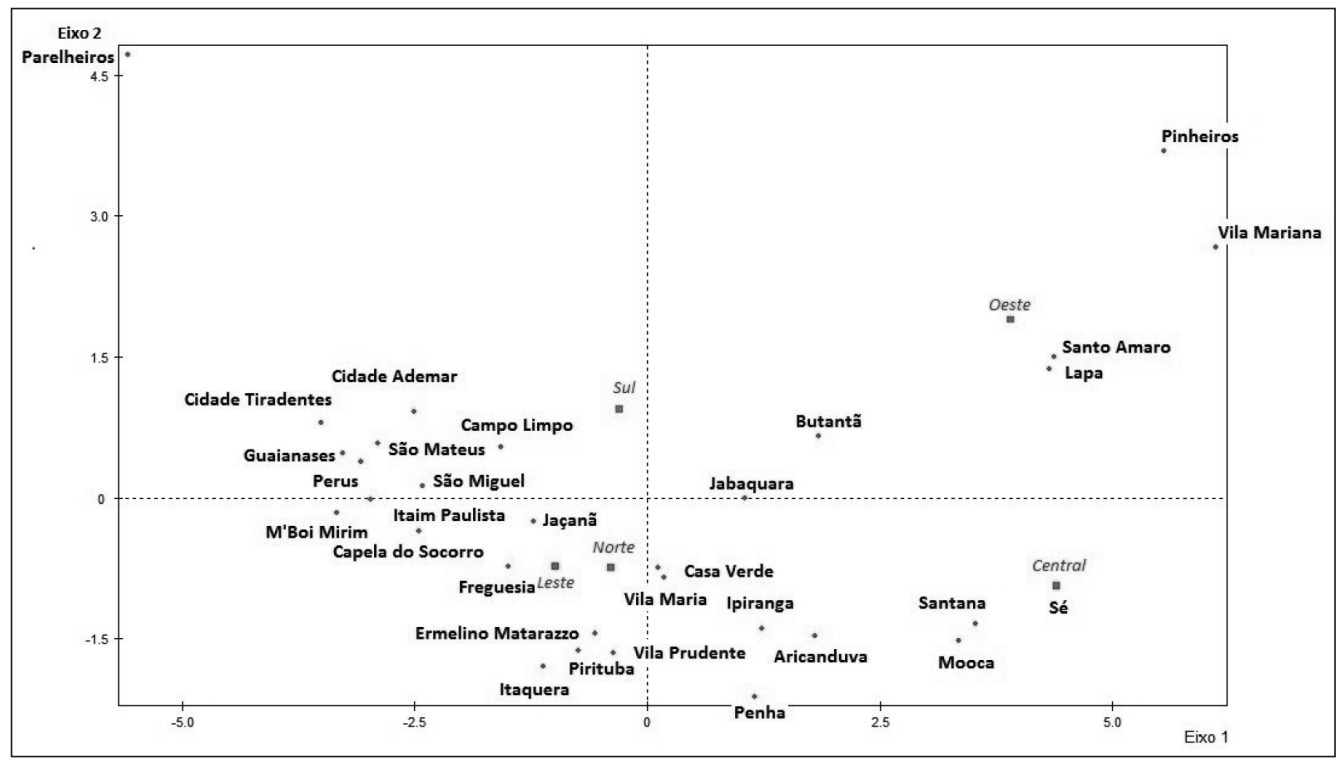

Fonte: Elaboração dos autores.

Figura 3

Círculo de correlações das variáveis ativas

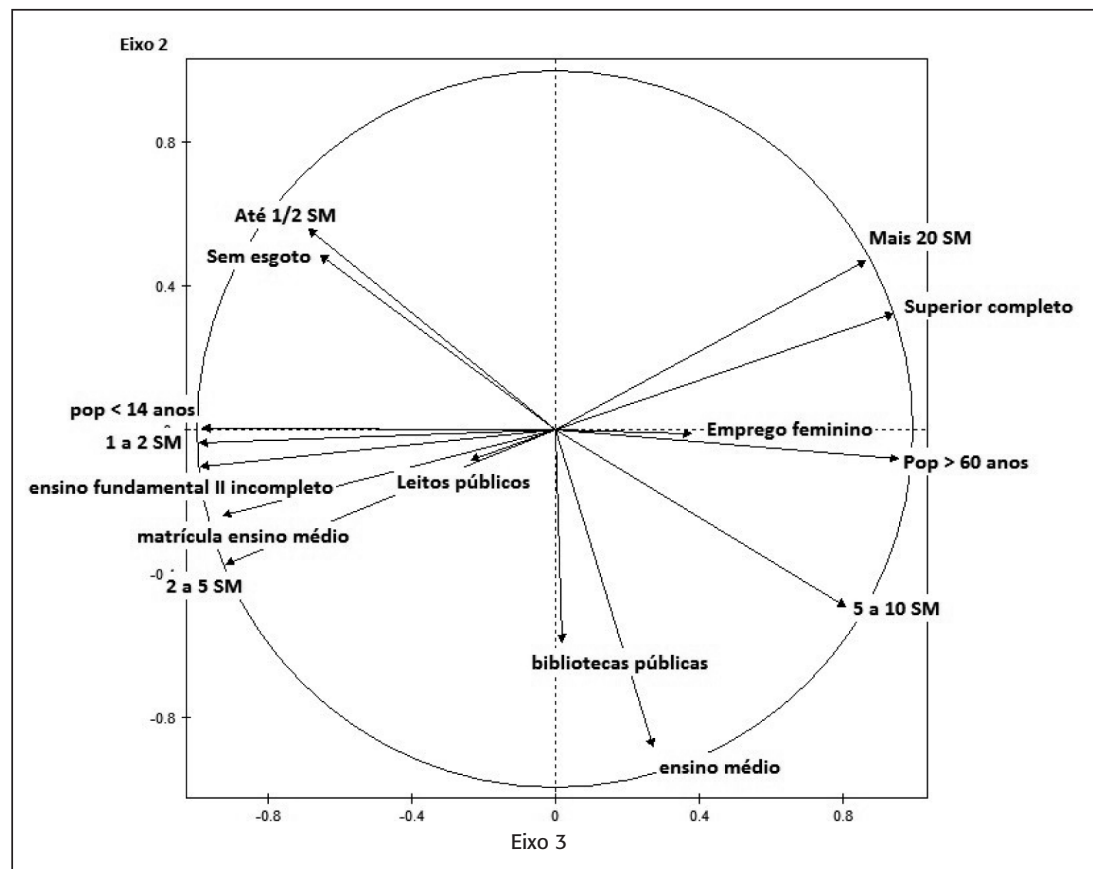

Fonte: elaboração dos autores 
A análise das variáveis ativas pode ser observada a partir do círculo de correlações e da matriz de correlações, que mostram os fatores que mais contribuíram para a definição dos eixos e, portanto, das diferentes configurações urbanas. As flechas longas da figura 3 apontam a direção e a intensidade dos fenômenos. Quanto mais curtas as flechas, mais bem distribuídos na estrutura social, definida pelos dois primeiros eixos.

As variáveis que mais contribuíram para o Eixo 1 foram a instrução, medida pela taxa da população que não completou o ensino fundamental II, e, na mesma magnitude, os domicílios com renda entre 1 e 2 salários mínimos, e a taxa da população menor de 14 anos: dimensões fortemente correlacionadas com o Eixo 1. Em seguida, tem-se também fortemente correlacionados com o Eixo 1 a população com idade superior a 60 anos, seguida da incidência da população com ensino superior, de domicílios com renda superior a $20 \mathrm{SM}$ e daqueles que recebem entre 5 e 10 SM (tabela 2).

Os fatores que mais contribuíram para o Eixo 2 foram, pela ordem, a posse do diploma de ensino médio $(+0,88)$ e a presença de bibliotecas públicas $(+0,59)$. A renda inferior a meio salário mínimo $(-0,56)$, os domicílios sem esgoto $(-0,48)$ e a renda superior a 20 SM são negativamente correlacionadas no Eixo 2. Por fim, o Eixo 3 possui como principal fator de contribuição os leitos públicos $(+0,75)$ e, em seguida, o emprego formal feminino $(+0,67)$.

Tabela 1

Correlações entre as variáveis e os fatores

\begin{tabular}{|lccccc|}
\hline 15 Variáveis Ativas & Eixo 1 & Eixo 2 & Eixo 3 & Eixo 4 & Eixo 5 \\
\hline População até 14 anos & $-0,98$ & 0,00 & 0,03 & $-0,02$ & $-0,04$ \\
População com mais de 60 anos & 0,95 & $-0,08$ & $-0,07$ & 0,01 & $-0,01$ \\
População com ensino fundamental II incompleto & $-0,99$ & $-0,10$ & $-0,04$ & 0,02 & $-0,02$ \\
População com ensino médio & 0,27 & $-0,88$ & $-0,10$ & $-0,06$ & $-0,19$ \\
População com ensino superior & 0,94 & 0,32 & 0,05 & $-0,01$ & 0,08 \\
Matrícula pública de ensino médio & $-0,92$ & $-0,24$ & $-0,04$ & $-0,09$ & $-0,03$ \\
Bibliotecas públicas & 0,02 & $-0,59$ & 0,29 & 0,53 & 0,53 \\
Até meio salário mínimo (SM) & $-0,68$ & 0,56 & 0,20 & 0,18 & $-0,01$ \\
Entre 1 e 2 SM & $-0,99$ & $-0,04$ & 0,07 & 0,04 & $-0,06$ \\
Entre 2-5 SM & $-0,92$ & $-0,38$ & $-0,03$ & $-0,01$ & $-0,08$ \\
Entre 5-10 SM & 0,81 & $-0,49$ & $-0,24$ & $-0,03$ & 0,00 \\
Mais 20 SM & 0,86 & 0,47 & 0,08 & $-0,03$ & 0,09 \\
Domićlios sem esgoto & $-0,65$ & 0,48 & $-0,33$ & 0,21 & 0,12 \\
Emprego formal feminino & 0,38 & $-0,01$ & 0,67 & 0,38 & $-0,49$ \\
Leitos públicos & $-0,23$ & $-0,08$ & 0,75 & $-0,52$ & 0,24 \\
\hline
\end{tabular}

Fonte: Elaboração dos autores. 
Examinando as figuras 2 e 3 de maneira sobreposta, nota-se à esquerda do eixo horizontal as subprefeituras que possuem os maiores percentuais da população que não completou o ensino fundamental II. Esse fator é fortemente correlacionado com a ocorrência de domicílios com renda entre 1 e 2 SM que caracterizam as nuvens das subprefeituras dos quadrantes à esquerda do eixo vertical, inferior e superior, como Cidade Tiradentes, Guaianazes e M’Boi Mirim. Como esperado, a dimensão principal que estrutura esse espaço é representada pelo Eixo 1, que opõe os bairros de maior renda e maior nível educacional às subprefeituras de menor renda e escolaridade, ratificando estudos sociodemográficos que apresentam os padrões de segregação do município de São Paulo (Ribeiro, 2000; Villaça, 2001; Torres et al., 2003).

A longevidade é fortemente correlacionada com as melhores condições de vida, corroborando estudos epidemiológicos e sociológicos que sugerem de que maneira as condições de trabalho e o acesso diferenciado aos serviços de saúde incidem sobre a saúde (Wilkinson, 2005; Buss e Pellegrini Filho, 2007). O emprego formal feminino, ainda que mais distribuído pela cidade, é mais frequente nas regiões de maior renda e escolaridade. Assim, a ênfase deste estudo dá-se menos no Eixo 1 e mais nos Eixos 2 e 3, que ajudam a nuançar essa realidade.

O Eixo 2 está relacionado tanto com a infraestrutura pública das subprefeituras como com a posse de uma forma intermediária de capital cultural (diploma de ensino médio), que distingue, nos quadrantes à direita da figura 2, as regiões com maior presença de domicílios de 5 a 10 SM (Santana, Mooca) daquelas nas quais predominam os de mais de 20 SM (Vila Mariana e Pinheiros). Esse mesmo fator distingue também as subprefeituras dos quadrantes à esquerda, distanciando regiões como Penha ou Ermelino Matarazzo de regiões como Cidade Tiradentes ou M’Boi Mirim. Uma interpretação possível das correlações encontradas no Eixo 2 diz respeito ao papel "protetor" do diploma de ensino médio em relação às situações de grande pobreza e miséria que os indicadores de renda inferior a $1 / 2$ SM e sem saneamento indicam. Pinheiros e Parelheiros ocupam posições semelhantes no Eixo 2, embora no Eixo 1 possuam posições diametralmente opostas. Essas subprefeituras, por motivos opostos, possuem taxas menores da população com nível de ensino médio.

Leitos públicos $(+0,75)$ e o emprego formal feminino $(+0,65)$ são as variáveis mais correlacionadas ao Eixo 3. Embora essas duas variáveis estejam presentes em toda a cidade, nota-se, observando-se a tabela 2 como a incidência do emprego formal feminino cresce em direção às regiões ocupadas pelas classes médias e altas. Os leitos públicos são mais presentes nas regiões intermediárias das subprefeituras do quadrante inferior esquerdo (figura 2), como Jaçanã e Ermelino Matarazzo. Contudo, a flecha mais curta (na figura 3) e os coeficientes de correlação mostram que se trata de uma variável que incide, com magnitudes diferentes, em distintas regiões da cidade, sendo menos frequente nas regiões das periferias mais precárias, (como Cidade Tiradentes ou, particularmente, Parelheiros).

A partir da análise multidimensional do espaço social e geográfico de São Paulo podese afirmar que o eixo sociodemográfico ainda corresponde por $60 \%$ de sua definição. Mesmo com a identificação de outras dimensões importantes, o peso da dimensão socioeconômica se 
impõe à análise. Examina-se, a seguir, como as patologias sociais estão correlacionadas aos eixos e entre si.

Indaga-se em que medida o conjunto de dados levantados permite analisar os fatores que explicam as variações de bem-estar nas subprefeituras e a distribuição das patologias sociais. Trata-se de refletir sobre dimensões "objetivas" e "subjetivas" da vida social, normalmente separadas. Observe-se, na figura 4, as correlações entre as patologias sociais e os eixos definidos pelas variáveis ativas.

Figura 4

Círculo de correlações das variáveis suplementares

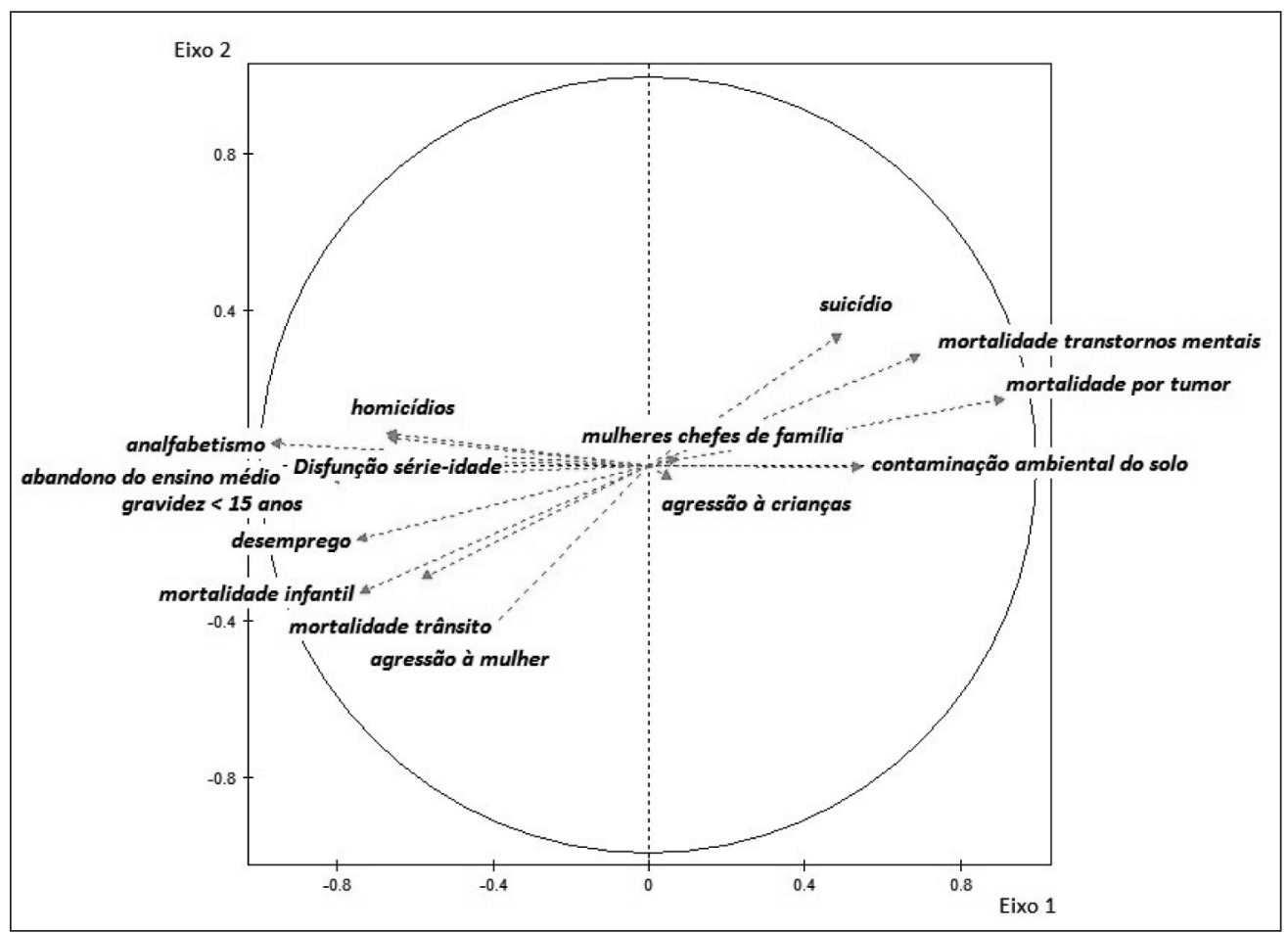

Fonte: Elaboração dos autores.

Tabela 2

Correlações de variáveis suplementares e os eixos

\begin{tabular}{|lccccc|}
\hline 15 Variáveis suplementares & Eixo 1 & Eixo 2 & Eixo 3 & Eixo 4 & Eixo 5 \\
\hline Taxa de chefia familiar feminina & 0,07 & 0,02 & $-0,01$ & $-0,15$ & $-0,02$ \\
Taxa de gravidez antes de 15 anos & $-0,82$ & $-0,03$ & $-0,10$ & $-0,11$ & 0,07 \\
Taxa de mortalidade infantil & $-0,74$ & $-0,33$ & 0,24 & 0,06 & $-0,26$ \\
Taxa de mortalidade no trânsito & $-0,58$ & $-0,29$ & $-0,01$ & $-0,12$ & 0,00 \\
Taxa de homicídios & $-0,67$ & 0,08 & $-0,27$ & 0,08 & 0,25 \\
\hline
\end{tabular}




\begin{tabular}{|lccccc|}
\hline 15 Variáveis suplementares & Eixo 1 & Eixo 2 & Eixo 3 & Eixo 4 & Eixo 5 \\
\hline Taxa de suicídio & 0,49 & 0,34 & 0,00 & $-0,03$ & 0,13 \\
Taxa de mortalidade por tumor & 0,91 & 0,17 & $-0,12$ & $-0,11$ & 0,07 \\
Taxa de mortalidade por transtorno mental & 0,69 & 0,29 & 0,08 & 0,08 & 0,03 \\
Taxa de abandono do ensino médio & $-0,82$ & 0,02 & 0,26 & 0,10 & $-0,06$ \\
Taxa de disfunção série/idade & $-0,67$ & 0,07 & $-0,07$ & 0,04 & 0,14 \\
Taxa de analfabetismo & $-0,97$ & 0,06 & $-0,04$ & $-0,01$ & 0,08 \\
Taxa de desemprego & $-0,75$ & $-0,19$ & 0,10 & 0,03 & 0,02 \\
Taxa de violência contra a mulher & $-0,42$ & $-0,44$ & 0,28 & $-0,29$ & $-0,19$ \\
Taxa de violência contra a criança & 0,06 & $-0,03$ & 0,19 & $-0,24$ & $-0,03$ \\
Número de áreas contaminadas & 0,55 & 0,00 & $-0,12$ & 0,03 & 0,17 \\
\hline
\end{tabular}

Fonte: Elaboração dos autores.

Quase todas as variáveis de patologias sociais consideradas neste estudo estão fortemente correlacionadas ao Eixo 1. O exame das correlações é realizado tendo-se como critério que duas variáveis são correlacionadas quando o coeficiente bivariado (coeficiente de Bravais -Pearson) é superior em valor absoluto a 0,40 , sendo, portanto, fortemente correlacionadas a partir de 0,70 (Lebaron, 2006).

Observando-se a matriz de correlações das variáveis suplementares com os eixos, as variáveis mais fortemente correlacionadas ao Eixo 1 foram as taxas de analfabetismo $(-0,97)$, de gravidez antes dos 15 anos $(-0,82)$ e de abandono do ensino médio $(-0,82)$, seguidas das taxas de desemprego $(+0,75)$ e de mortalidade infantil $(-0,74)$ que se apresentam negativamente correlacionadas ao Eixo 1. A taxa de mortalidade por tumor $(+0,91)$ está positivamente correlacionada ao Eixo 1. Em seguida, há outras correlações importantes com o Eixo 1, como a mortalidade por transtorno mental $(+0,69)$, os homicídios $(-0,67)$, a disfunção série/idade $(-0,67)$, as áreas de contaminação ambiental $(+0,55)$ e a taxa de suicídio $(+0,49)$. Há ainda um segundo grupo de variáveis correlacionadas com o Eixo 1, mas com menor intensidade que as variáveis precedentes. Trata-se de fenômenos que estão correlacionados com o Eixo 1, entretanto mais bem distribuídos pela cidade, como a mortalidade por acidente de trânsito $(-0,58)$, as áreas contaminadas $(+0,55)$ e a taxa de violência contra a mulher $(-0,42)$. Note-se que as variáveis "agressão às crianças" e "chefia familiar feminina" não estão correlacionadas ao Eixo 1 nem ao Eixo 2, sendo distribuídas de maneira plus uniforme na estrutura social, com incidência um pouco superior nas regiões de maior renda e maior escolaridade, ao contrário do que poderia supor o senso comum.

O Eixo 2 é fragilmente correlacionado às variáveis suplementares, e quase todas as patologias sociais que foram incluídas neste estudo são fortemente associadas ao Eixo 1, tais como a pobreza e o desenvolvimento econômico e social nas subprefeituras. A variável mais fortemente correlacionada ao Eixo 2 foi a taxa de agressão às mulheres $(-0,44)$. Note-se que essa variável também é correlacionada ao Eixo 1 em -0,42, ou seja, é mais incidente nas subprefeituras de periferia. Essa taxa (agressão às mulheres) é um pouco mais correlacionada 
ao Eixo 2 porque se trata de fenômeno mais frequente nas periferias intermediárias, em que predomina o ensino médio, casos de Ermelino Matarazzo ou Itaquera, do que nas subprefeituras mais precárias, como Cidade Tiradentes ou Cidade Ademar (figura 2).

\section{Considerações finais}

Este trabalho corrobora a tese de que a maior parte das patologias sociais em São Paulo está fortemente correlacionada ao Eixo 1, referentes à pobreza e à riqueza, ou seja, o peso da dimensão econômica é significativo. Nesse sentido, por meio de gráficos e tabelas analisados pode-se verificar que há um conjunto de patologias sociais relacionadas a ambos, como a reprovação escolar e o abandono do ensino médio, a gravidez antes dos 15 anos, o desemprego e os homicídos que afetam mais fortemente as regiões mais pobres da cidade: a maioria da população.

Os indicadores sociais selecionados neste estudo identificaram as patologias sociais relacionadas com o desenvolvimento econômico e social, como a taxa de mortalidade no trânsito, que é um indicador afetado especialmente pelo número de acidentes de motocicletas, cujas vítimas são homens jovens de baixa renda, prestadores de serviços. ${ }^{16}$ Já o indicador de degradação do meio ambiente é mais incidente nas regiões de antiga industrialização na cidade, como as subprefeituras da Mooca ou da Lapa.

Variáveis como suicídio, mortalidade por transtorno mental e por tumor concentram-se nas regiões mais ricas da cidade; neste último caso, em razão da maior longevidade desses grupos. Já a mortalidade por transtorno mental e stress tende a aumentar com o desenvolvimento econômico, especialmente em contextos de intensificação do trabalho e de aumento da concorrência em escala mundial (Lebaron et al., 2013).

O caso do suicídio, mais complexo, possibilita analisar as patologias sociais para além das condições de vida. Bourdieu (1998) alerta para os riscos de se ater apenas à "grande miséria", desconsiderando-se outras formas de sofrimento social que derivam mais da "miséria de posição" do que da "miséria de condição". Portanto, há, por um lado, as patologias sociais referentes à miséria econômica e, por outro, a "miséria de posição", que opõe os indicadores de violência física (sobretudo o homicídio) aos indicadores de violência simbólica (reprovação escolar, fragilidade dos vínculos familiares, sentimento de insegurança, cujo caso extremo é o suicídio, entre outros). Mesmo a agressão às mulheres, fenômeno correlacionado com os Eixos 1 e 2, é revelador da "miséria de posição", pois mais frequente entre as mulheres que vivem nas periferias e nas regiões com maior nível de escolaridade (ensino médio).

Observa-se, ainda, como a distribuição das patologias sociais está ligada aos níveis de escolaridade, caso do suicídio (nas regiões da cidade onde predomina o ensino superior). $\mathrm{O}$ diploma de ensino médio foi a variável que mais pesou na definição do eixo vertical (Eixo 2), diferenciando subprefeituras das periferias, como Cidade Tiradentes, Cidade Ademar, Ermelino Matarazzo e Itaquera (todas nos quadrantes à esquerda, figura 2).

\footnotetext{
${ }^{16}$ Disponível em: <www.seade.gov.br/wp-content/uploads/2014/06/Primeira_Analise_n2_maio_2013.pdf>. Acessado em: 30 jun. 2015.
} 
Se o uso de indicadores clássicos de patologias sociais pode servir para estigmatizar segmentos sociais, caso da criminalidade associada fortemente à pobreza, a utilização de conjunto mais amplo de indicadores contribui para desconstruir tais associações automáticas — e baseada em estereótipos — , caso, por exemplo, dos indicadores de agressão às mulheres e às crianças.

Procurou-se demonstrar que as taxas de agressão às mulheres, fortemente correlacionada ao eixo socioeconômico, não têm a mesma incidência nas subprefeituras das periferias mais precárias (casos de M’Boi Mirim, Cidade Tiradentes e Guaianazes) e nas periferias intermediárias (casos de Itaquera, Ermelino Matarazzo e Pirituba), que se distinguem pelo nível de infraestrutura pública disponível e pelo maior percentual da população com ensino médio. A hipótese é que a agressão às mulheres pode estar relacionada com o casamento com parceiros com escolaridade mais baixa. O caso da taxa de agressão às crianças é ainda mais emblemático, pois, ao contrário do que supõe o senso comum, é distribuído por toda a estrutura social, com leve inclinação para as regiões de renda intermediária. Note-se que as políticas públicas e o aparato da Administração Pública ganham em eficácia e efetividade em considerar esses dados mais finos e complexos. O “campo de públicas" necessita, portanto, ampliar os horizontes para essas dimensões.

Sem a pretensão de esgotar a discussão possibilitada pelos dados, procurou-se apresentar panorama da estrutura social multidimensional com vistas a contribuir para novas hipóteses explicativas sobre as condições sociais dos grupos populacionais. Entende-se que há a necessidade de salto qualitativo na articulação de indicadores de diagnóstico, de impactos e de resultados de políticas públicas (Draibe, 2001) no âmbito da Administração Pública, pois fundamental aos tomadores de decisão em nível local.

A comparação dos indicadores sociais das subprefeituras pelo método ACP torna ainda mais visível que os indicadores sintéticos do município, baseados em médias municipais, como o IDH, ocultam diferenças consideráveis entre as regiões, caso do indicador de longevidade. Nas diferentes regiões da cidade a ocorrência é bastante desigual em razão da posição do indivíduo na estrutura social. Têm-se, assim, demonstrações empíricas dos determinantes sociais de saúde, que incluem as condições socioeconômicas, a escolaridade, as condições de vida e trabalho, mas também as condições de habitação, saneamento e acesso aos serviços de saúde (Adler e Newman, 2002). A relação entre nível socioeconômico e longevidade está relacionada não apenas às dificuldades de acesso aos serviços de saúde, mas também às más condições de trabalho ao longo do ciclo de vida (Athias-Donfut, 1983).

Portanto, os resultados do presente estudo corroboram estudos sobre a pertinência da dimensão territorial e a insuficiência da oposição simplista centro-periferia para compreender os problemas sociais das metrópoles brasileiras (Villaça, 2001; Torres et al., 2003). Também corroboram estudos sobre a heterogeneidade das periferias, tanto em relação à precariedade da infraestrutura pública como à incidência de patologias sociais que podem ser mensuradas por novos indicadores, quantitativos e qualitativos. Em decorrência, as respostas do poder público, notadamente da Administração Pública, por meio das políticas públicas e dos aparatos estatais, podem alterar relativamente as análises acerca das posições sociais de grupos vulneráveis. Afinal, passam a ter conhecimento de problemas que são apenas aparentemente semelhantes. 
Análises diagnósticas e de impacto em políticas públicas a partir da perspectiva de diversos atores sociais, políticos ou institucionais podem ganhar maior densidade pelo método ACP, especialmente a tarefa urgente de estruturação de sistemas de indicadores de monitoramento e de avaliação nos três níveis de governo, "[...] sob pena de estender, por mais tempo ainda, a superação das iniquidades sociais no país e com o risco de se perder a crença de que os programas públicos podem ser vetores impactantes de mudança social no Brasil" (Jannuzzi, 2011:272).

Por fim, enfatize-se que a compreensão das diferenças ocultadas no interior de supostas semelhanças é a grande contribuição desse tipo de análise estatística à gestão pública. Notadamente, a técnica da ACP permite visualizar o universo multidimensional do conjunto da cidade, que não se reduz à dimensão econômica, embora seja fortemente determinado por ela. Nesse sentido, o estudo deste conjunto de indicadores aqui analisados possibilita a compreensão de dinâmicas sociais ainda mais complexas e contraditórias da macrometrópole de São Paulo. Isso implica a necessidade de novos paradigmas, uma vez que podem afetar a forma de atuação da Administração Pública, de sua gestão e das políticas públicas, cujos efeitos podem beneficiar fortemente os mais vulneráveis.

\section{Referências}

ADLER, Nancy; NEWMAN, Katherine. Socioeconomic disparities in health: pathways and policies. Health affairs, v. 21, n. 2, p. 60-76, 2002.

ARRETCHE, Marta. Democracia, federalismo e centralização no Brasil. Rio de Janeiro: Editora FGV; Editora Fiocruz, 2012.

ATTIAS-DONFUT, Claudine. La vieillesse inégale. Communications, v. 37, n. 1, p. 125-136, 1983.

BAUDELOT, Christian; ESTABLET, Roger. Allez les filles! Paris: Le Seuil, 1992.

BAUDELOT, Christian; ESTABLET, Roger. Suicide. L'envers de notre monde. Paris: Le Seuil, 2006.

BERQUÓ, Elza; CAVENAGHI, Suzana. Fecundidade em declínio: breve nota sobre a redução no número médio de filhos por mulher no Brasil. Novos Estudos - Cebrap, n. 74, p. 11-15, 2006.

BOURDIEU, Pierre. A miséria do mundo. Petrópolis: Vozes, 1998.

BOURDIEU, Pierre. Espaço social e gênese das classes. In: BOURDIEU, Pierre. O poder simbólico. Rio de Janeiro: Bertrand Brasil, 2011.

BOURDIEU, Pierre. La distinction. Paris: Seuil, 1979.

BRUSCHINI, Cristina; LOMBARDI, Maria Rosa. Instruídas e trabalhadeiras: trabalho feminino no final do século XX. Cadernos Pagu, Campinas, n. 17-18, p. 157-196, 2002.

BUSS, Paulo M.; PELLEGRINI FILHO, Alberto. A saúde e seus determinantes sociais. Physis, v. 17, n. 1, p. 77-93, 2007.

CASTEL, Robert. As metamorfoses da questão social: uma crônica do salário. Tradução de Iraci D. Poleti. Petrópolis: Vozes, 2012. 
DRAIBE, Sonia M. Avaliação de implementação: esboço de uma metodologia de trabalho em políticas públicas. In: BARREIRA, Maria Cecília R. N.; CARVALHO, Maria do C. B. (Org.). Tendências e perspectivas na avaliação de políticas e programas sociais. São Paulo: IEE/PUC-SP, 2001.

DURKHEIM, Émile. O suicídio. São Paulo: Martins Fontes, 2011.

FARAH, Marta F. S. Administração pública e políticas públicas. Rev. Adm. Pública, Rio de Janeiro, v. 45, n. 3, p. 813-836, maio/jun. 2011.

FARIA, Flavia P.; JANNUZZI, Paulo de M.; SILVA, Silvano José da. Eficiência dos gastos municipais em saúde e educação: uma investigação através da análise envoltória no estado do Rio de Janeiro. Rev. Adm. Pública, Rio de Janeiro, v. 42, n. 1, p. 155-177, fev. 2008.

FONSECA, Francisco; BELTRÃO, Ricardo; PRADO, Otávio. Avaliando a capacidade de governo: reflexões sobre a experiência do Prêmio "Municípios que Fazem Render Mais" (2010 e 2011). Rev. Adm. Pública, Rio de Janeiro, v. 47, n. 1, p. 249-272, jan./fev. 2013.

GADREY, Jean; JANY-CATRICE, Florence. Os novos indicadores de riqueza (tradução de "Les nouveaux indicateurs de richesse"). São Paulo: Senac, 2006.

JANNUZZI, Paulo de M. Avaliação de programas sociais no Brasil: repensando práticas e metodologias das pesquisas avaliativas. Planejamento e Políticas Públicas - PPP, n. 36, jan./jun. 2011. Disponível em: <www.ipea.gov.br/ppp/index.php/PPP/issue/view/30> . Acesso em: 30 jun. 2015.

JANNUZZI, Paulo de M. Indicadores Sociais no Brasil: conceitos, fontes de dados e aplicações. Campinas, SP: Alínea, 2004.

KAYANO, Jorge; CALDAS, Eduardo de L. Indicadores para o diálogo. In: CACCIA-BAVA, Silvio; PAULICS, Veronika; SPINK, Peter (Org.). Novos contornos da gestão local: conceitos em construção. São Paulo, Pólis; Programa Gestão Pública e Cidadania/FGV-Eaesp, 2002.

KUGELMAS, Eduardo. A evolução recente do regime federativo no Brasil. In: HOFMEISTER, Wilhelm; CARNEIRO, José Mário B. (Ed.). Federalismo na Alemanha e no Brasil. São Paulo: Konrad-Adenauer Stiftung, 2001. p. 29-49.

LAZARSFELD, Paul; JAHODA, Marie; ZEISEL, Hans. Les chômeurs de Marienthal. Paris: Éditions de Minuit, 1981.

LEBARON, Frédéric; GAUBERT, Christophe; POULY, Marie-Pierre. L'enquête quantitative en sciences sociales. Paris: Dunod, 2006.

LEBARON, Frédéric; GAUBERT, Christophe; POULY, Marie-Pierre. Les indicateurs sociaux au vingtet-unième siècle. Paris: Dunod, 2011.

LEBARON, Frédéric; GAUBERT, Christophe; POULY, Marie-Pierre. Manuel visuel de sociologie. Paris: Dunod, 2013.

LEITE, Cristiane Kerches da Silva; FONSECA, Francisco. Federalismo e políticas sociais no Brasil: impasses da descentralização pós-1988. Revista Organização \& Sociedade, v. 18, n. 56, p. 99-117, 2011.

MARQUES, Eduardo. Estrutura social e segregação em São Paulo: transformações na década de 2000. Dados, Rio de Janeiro, v. 57, n. 3, p. 675-710, 2014. 
MARQUES, Eduardo; FARIA, Carlos A. P. de (Org.). A política pública como campo multidisciplinar. São Paulo: Editora Unesp; Rio de Janeiro: Editora Fiocruz, 2013.

MIRINGOFF, Marque-Luisa; OPDYCKE, Sandra. America's social health: putting social issues back on the public agenda. Armonk, NY; Londres: M. E. Sharpe, 2008.

MOKATE, Karen Marie. Convirtiendo el "monstruo" en aliado: la evaluación como herramienta de la gerencial social. Revista do Serviço Público, v. 53, n. 1, p. 89-134, jan./mar. 2002.

PAULANI, Leda Maria; BRAGA, Marcio B. A nova contabilidade social: uma introdução à microeconomia. São Paulo: Saraiva, 2006.

PIRES, Valdemir et al. Dossiê — Campo de públicas no Brasil: definição, movimento constitutivo e desafios atuais. Administração Pública e Gestão Social - APGS, v. 6, n. 3, p. 110-126, jul./set. 2014.

REIS, Paulo R. da C.; SILVEIRA, Suely de F. R.; RODRIGUES, Pedro E. L. Impactos da Política Nacional de Irrigação sobre o desenvolvimento socioeconômico da região Norte de Minas Gerais: uma avaliação do Projeto Gorutuba. Rev. Adm. Pública, Rio de Janeiro, v. 46, n. 4, p. 1101-1130, 2012.

RIBEIRO, Luiz Cesar de Q.; LAGO, Luciana C. O espaço social das grandes metrópoles brasileiras - São Paulo, Rio de Janeiro e Belo Horizonte. Revista Brasileira de Estudos Urbanos e Regionais, n. 3, p. 111-129, out. 2000.

RINGER, Fritz. O declínio dos mandarins alemães. São Paulo: Edusp, 2001.

SCRIPTORE, Juliana S.; TONETO JUNIOR, Rudinei. A estrutura de provisão dos serviços de saneamento básico no Brasil: uma análise comparativa do desempenho dos provedores públicos e privados. Rev. Adm. Pública, Rio de Janeiro, v. 46, n. 6, p. 1479-1504, 2012.

SEN, Amartya. Desenvolvimento como liberdade. São Paulo: Companhia das Letras, 2000.

SEN, Amartya. Prefácio. In: PNUD. Desenvolvimento humano: leituras selecionadas. Belo Horizonte: PUC Minas, 2007. p. 9-15.

SENNET, Richard. The corrosion of character: the personal consequences of work in the new capitalism. Nova York: W. W. Norton \& Company, 1998.

STIGLITZ, Joseph; SEN, Amartya; FITOUSSI, Jean-Paul. Performances économiques et progrès social. Paris: Odile Jacob, 2009. 2 t.

STUCKLER, David; BASU, Sanjay. The body economic: why austerity kills. Nova York: Basic Books, 2013.

TORRES, Haroldo da G. et al. Pobreza e espaço: padrões de segregação em São Paulo. Estudos Avançados, São Paulo, v. 17, n. 47, p. 97-128, 2003.

VAN BELLEN, Hans Michael. Indicadores de sustentabilidade: um levantamento dos principais sistemas de avaliação. Cad. EBAPE.BR, Rio de Janeiro, v. 2, n. 1, p. 01-14, mar. 2004.

VEIGA, José E. Desenvolvimento sustentável, o desafio do século XXI. 3. ed. Rio de Janeiro: Garamond Universitária, 2008. 
VIEIRA, Marcelo M. F. et al. Indicadores de qualidade na administração municipal: um estudo exploratório na prefeitura da cidade de Recife. Revista de Administração Contemporânea, Curitiba, v. 4, n. 1, p. 69-91, abr. 2000.

VILLAÇA, Flávio. Espaço intra-urbano no Brasil. 2. ed. São Paulo: Studio Nobel; Fapesp, Lincoln Institute, 2001.

WEBER, Max. Os letrados chineses. In: WEBER, Max. Ensaios de sociologia. Rio de Janeiro: Zahar, 1974.

WILKINSON, Richard G. The impact of inequality: how to make sick societies healthier. Londres: Routledge, 2005.

Graziela Serroni Perosa é doutora em educação pela Universidade Estadual de Campinas (Unicamp, 2005). Professora da Universidade de São Paulo, na Escola de Artes, Ciências e Humanidades (EACH/ USP). Professora do Programa de Pós-Graduação em Estudos Culturais na EACH e Coordenadora do Ciclo Básico da EACH (2013-15). Email: grazielaperosa@yahoo.com.br.

Cristiane Kerches da Silva Leite é doutora em ciência política pela Universidade de São Paulo (USP, 2006). Professora da graduação e pós-graduação em gestão de políticas públicas da Escola de Artes, Ciências e Humanidades da Universidade de São Paulo (EACH/USP). Email: criskerches@gmail.com.

Francisco Fonseca é doutor em história social pela Universidade de São Paulo (USP, 2001). Professor de ciência política da Fundação Getulio Vargas de São Paulo (FGV/Eaesp) e da Pontifícia Universidade Católica de São Paulo (PUC-SP). Ministra aulas na graduação em Administração de Empresas e Administração Pública e no Programa de Pós-Graduação em Administração Pública e Governo. Pesquisador do Centro de Estudos em Administração Pública e Governo (Ceapg) da FGV/Eaesp. Email: franciscocpfonseca@gmail.com.

Frédéric Lebaron é doutor em sociologia pela Escola de Altos Estudos em Ciências Sociais de Paris (EHESS). Professor de sociologia da Universidade de Versailles Saint-Quentin-em-Yvelines, membro da Universidade Paris-Sarclay e da Sciences Po Saint-Germain-em-Laye. Dirigiu o Centro universitário de pesquisa sobre Ação pública e epistemologia em ciências sociais na Universidade Picardie — Jules Verne, entre 2005 e 2013. Atualmente é pesquisador do laboratório Printemps na Universidade de Versailles Saint-Quentin-em-Yvelines. Email: flebaron@yahoo.com.fr. 